\title{
Impact of the additional parking space on parallel parking maneuver time
}

\author{
Rudy Setiawan ${ }^{1, *}$ \\ ${ }^{1}$ Petra Christian University, Depart. of Civil Engineering, Surabaya, Indonesia
}

\begin{abstract}
The study reports the effect of additional parking space for the tandem parking upstream stall and downstream stall to reduce parking maneuver time compare with conventional parallel parking maneuver time. The experiments involving 295 students of Petra Christian University. Results indicate that, added one-meter additional parking space could reduce total maneuver time up to $29 \%$ for the upstream stall and $31 \%$ for the downstream stall, and also reduce $8 \%$ income from on-street parking fee, but also will reduce $35 \%$ loss due to the delay time caused by parallel parking maneuver.
\end{abstract}

\section{Introduction}

The availability of the car park is an inevitability for car user and will ease car user, especially when car park location is near by their destination. However, there are car park configurations that will affect the travel time of adjacent traffic flow causing by parking maneuver, specifically conventional parallel on-street parking.

Recently, car manufacturers have added intelligent vehicle parking assist systems to the car due to difficulties in parallel parking [1-3]. However, that feature takes a few years to become available for any cars [4]. Therefore, it is necessary to find an alternative to minimize parallel parking maneuver time.

One alternative to reduce the delay time of adjacent traffic flow due to parallel parking maneuvers is to use a tandem parking system, both upstream stall and downstream stall [5]. Although the drawbacks of tandem parking system are reduced efficiency the use of parking space and encourages on-street parking [6].

The study reports the effect of additional parking space for the tandem parking upstream stall and downstream stall to reduce parking maneuver time compare with conventional parallel parking maneuver time.

\subsection{Parallel parking}

Conventional parallel parking is a parking layout, in which car was parked parallel to the road in line with other parked cars (Figure 1). For few drivers, parallel parking maneuver is considered difficult and is required in test to get the car-driving license in Indonesia.

\footnotetext{
* Corresponding author: rudy@petra.ac.id
} 
Conventional parallel parking enables the driver to park a car in a smaller space. Conventional parallel parking enables the driver to park a car in a smaller space. Reversing approach into the empty parallel parking space allows the driver to take advantage of an empty parking space a little bit longer than the car dimension.

One of the issues that arise from the on-street parallel parking is the maneuver time that affects travel time to the adjacent traffic. Tandem parallel parking both upstream stall and downstream stall, in which two cars were parked with additional parking space between them, the additional parking space could be used to ease entry and exit maneuver (Figure 2 and Figure 3), are an option to reduce delay time causing by maneuver time compare with conventional parallel parking [5].

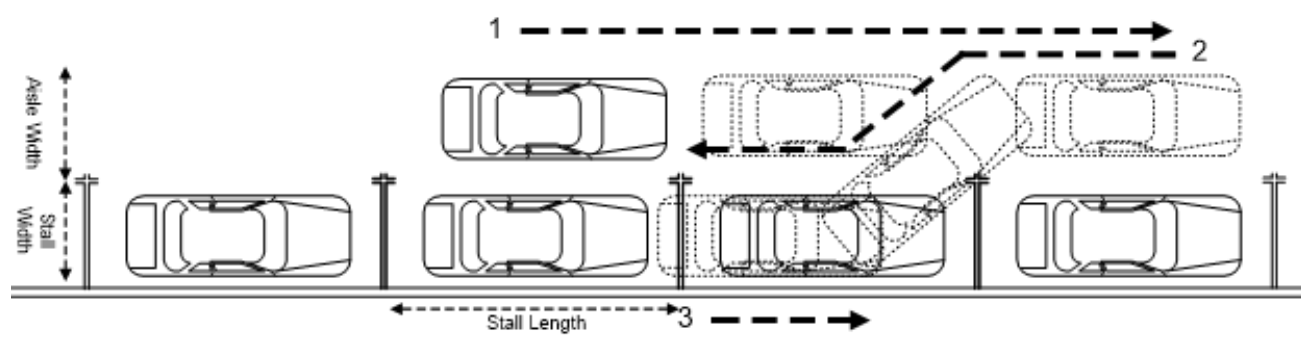

Fig. 1. Conventional parallel parking

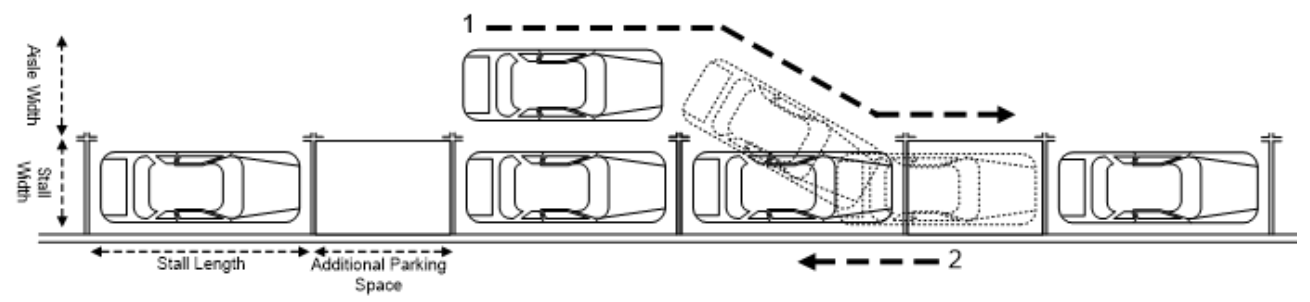

Fig. 2. Tandem parking upstream stall

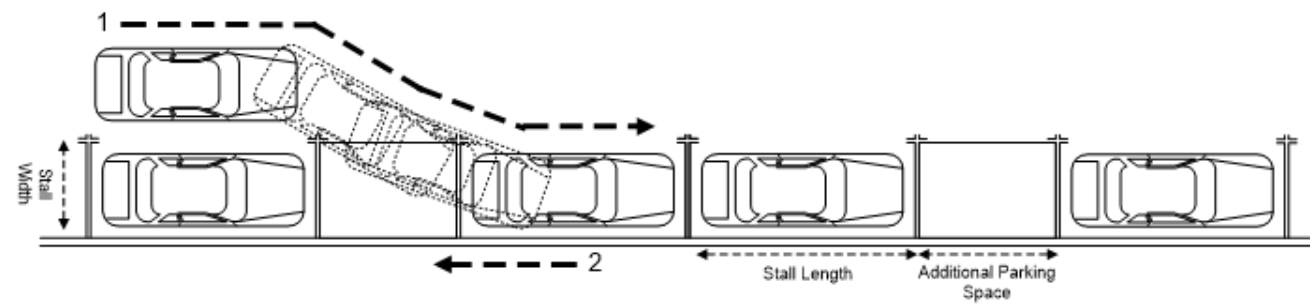

Fig. 3. Conventional parallel parking

\section{Methods}

The experiment involving 295 students of Petra Christian University, the car type varies from city car, sedan, Sport Utility Vehicle, Multi-Purpose Vehicle, and Double Cabin. The car dimension (length $\mathrm{x}$ width) participate in this experiment was varies from $3,410 \mathrm{~mm} \mathrm{x}$ $1,460 \mathrm{~mm}$ to $5,255 \mathrm{~mm} \times 2,154 \mathrm{~mm}$, and the average is $4,148 \mathrm{~mm} \times 1,710 \mathrm{~mm}$.

In this experiment, the dimension of parking space for the conventional parallel parking is $5,700 \mathrm{~mm} \times 2,400 \mathrm{~mm}$ (stall length $\mathrm{x}$ stall width), and aisle width is $2,700 \mathrm{~mm}$ [7]. The dimension of parking space for the upstream stall and downstream stall is the same as the 
conventional parallel parking, with the additional parking space varies between $1.0 \mathrm{~m}$ up to $4.5 \mathrm{~m}$ with $0.5 \mathrm{~m}$ interval.

The reduction of delay time to adjacent traffic causing by parallel maneuver time between conventional parallel parking and tandem parallel parking, compare using the Value of Time (VT). VT for Surabaya City at 2017 is IDR. 27,510 per car per hour, that obtain from the VT for Surabaya City at 2015 (IDR. 24,484) multiplied by interest rate 6\% [8].

\section{Results}

The average entry and exit maneuver time for the conventional parallel parking are 22.3 secs $(\mathrm{SD}=2.7)$ and $10.9 \mathrm{secs}(\mathrm{SD}=1.3)$ respectively. The entry maneuver time are longer than the exit maneuver time because for the entry maneuver driver need to do it in three steps, first positioning the car, second reversing approach into the parking space, and third adjusting parking position inside the parking space.

Compare with conventional parallel parking, both tandem parallel upstream and downstream stall with additional parking space from $1.0 \mathrm{~m}$ to $4.5 \mathrm{~m}$, have shorter maneuver time, both for entry maneuver (Figure 4 and Figure 5) and exit maneuver (Figure 6 and Figure 7). Additional parking space could reduce entry maneuver time about $39 \%$ to $72 \%$ (Figure 8 ), and reduce exit maneuver time about $2 \%$ to $40 \%$ (Figure 9) compare without additional parking space or conventional parallel parking. Overall, the difference of total maneuver time between conventional parallel parking and both tandem parking upstream stall and downstream stall about $29 \%$ to $60 \%$ (Figure 10)

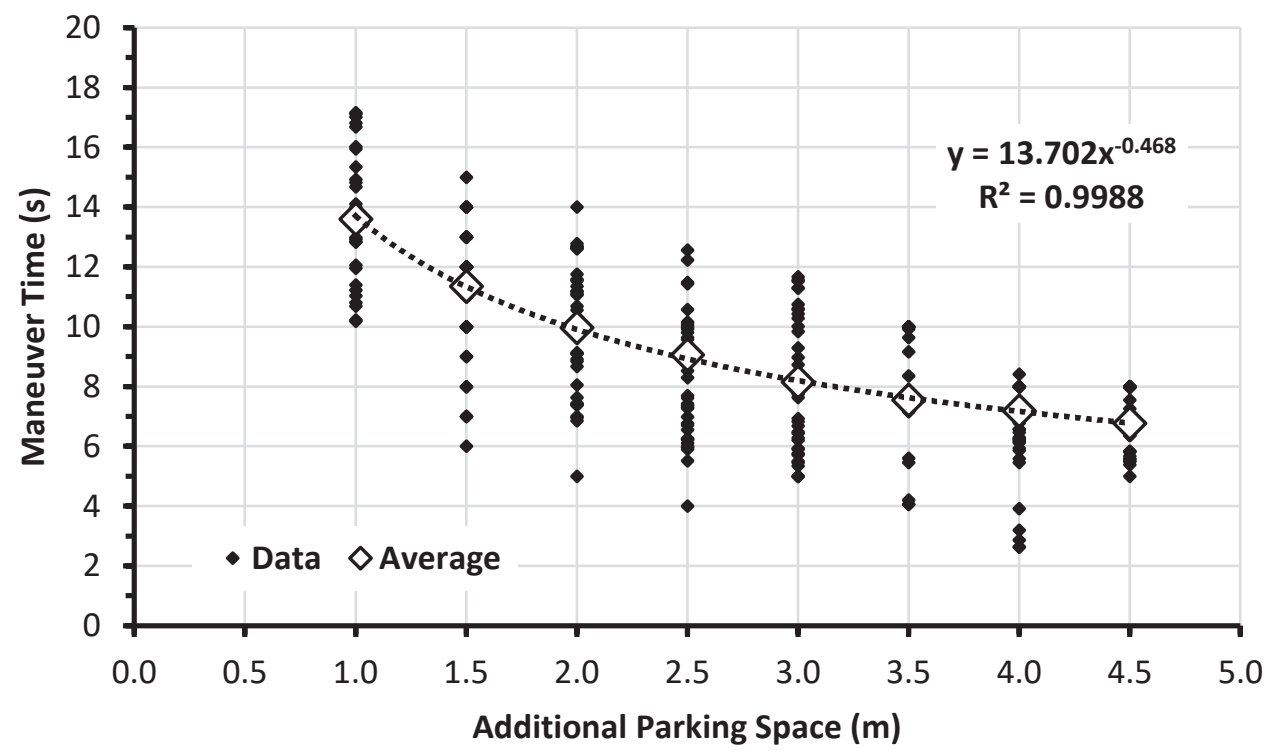

Fig. 4. Upstream stall entry maneuver time 


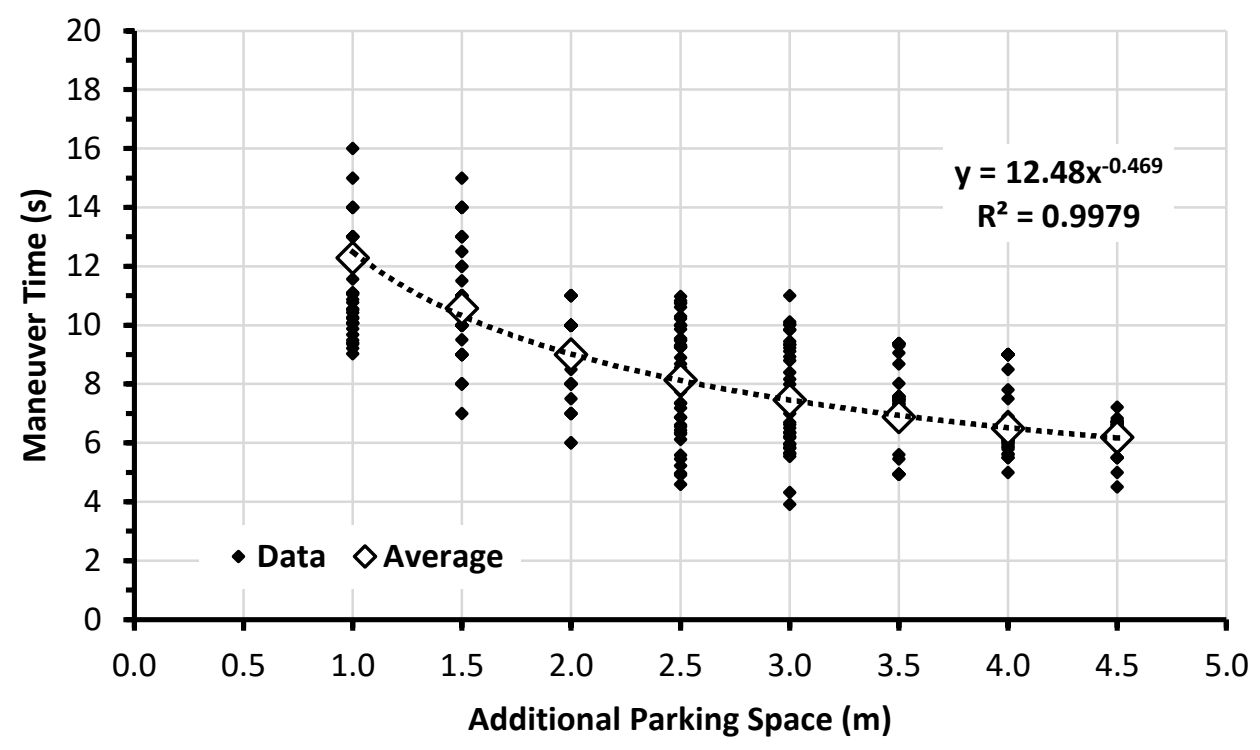

Fig. 5. Downstream stall entry maneuver time

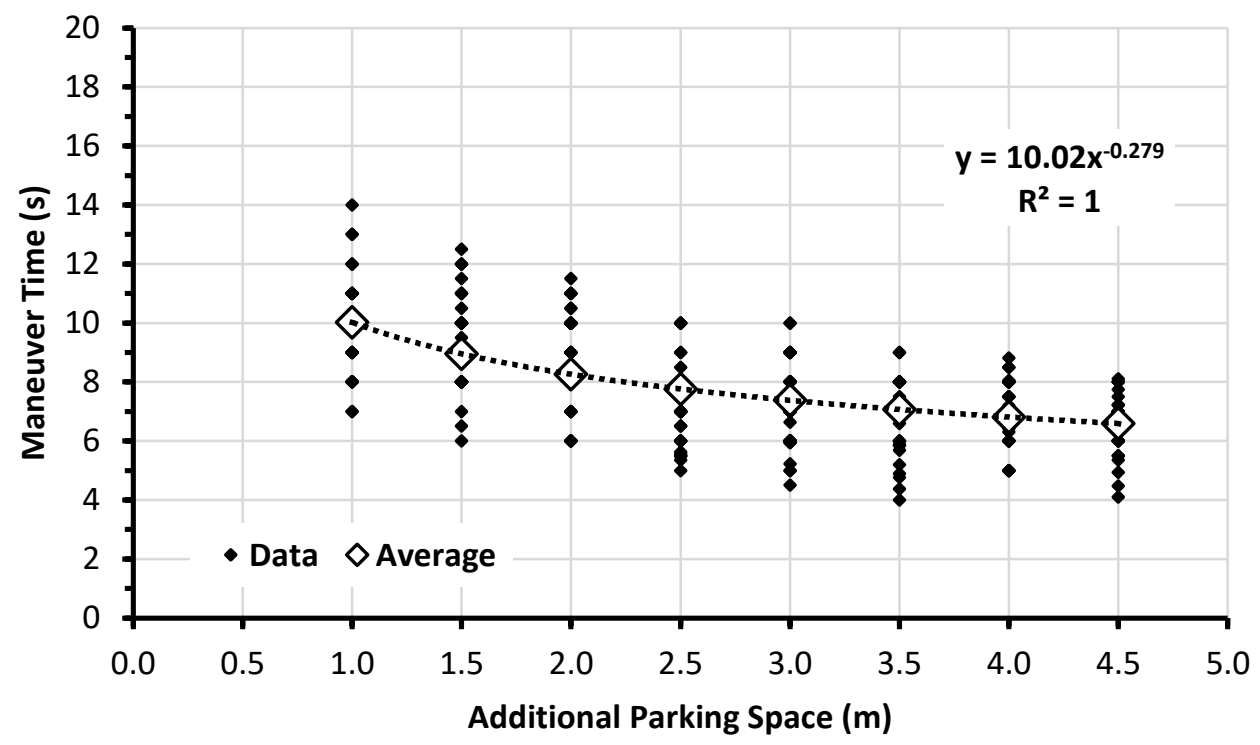

Fig. 6. Upstream stall exit maneuver time 


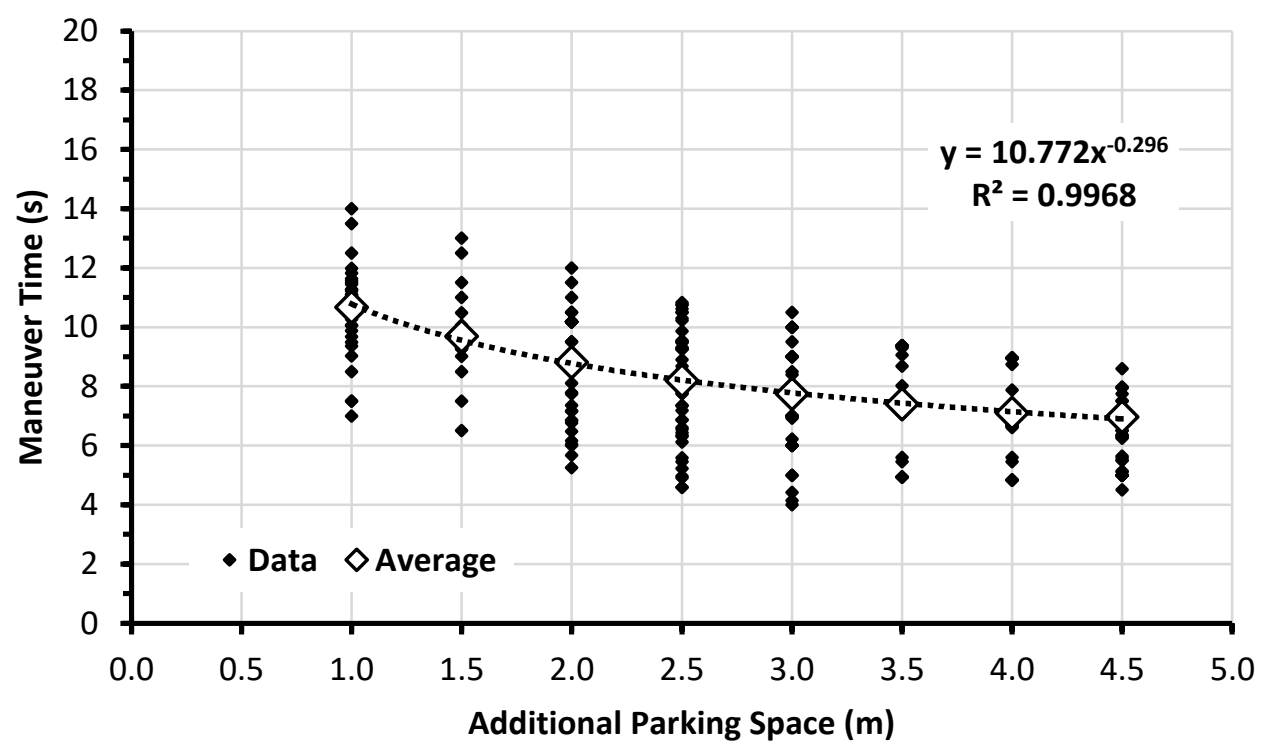

Fig. 7. Downstream stall exit maneuver time

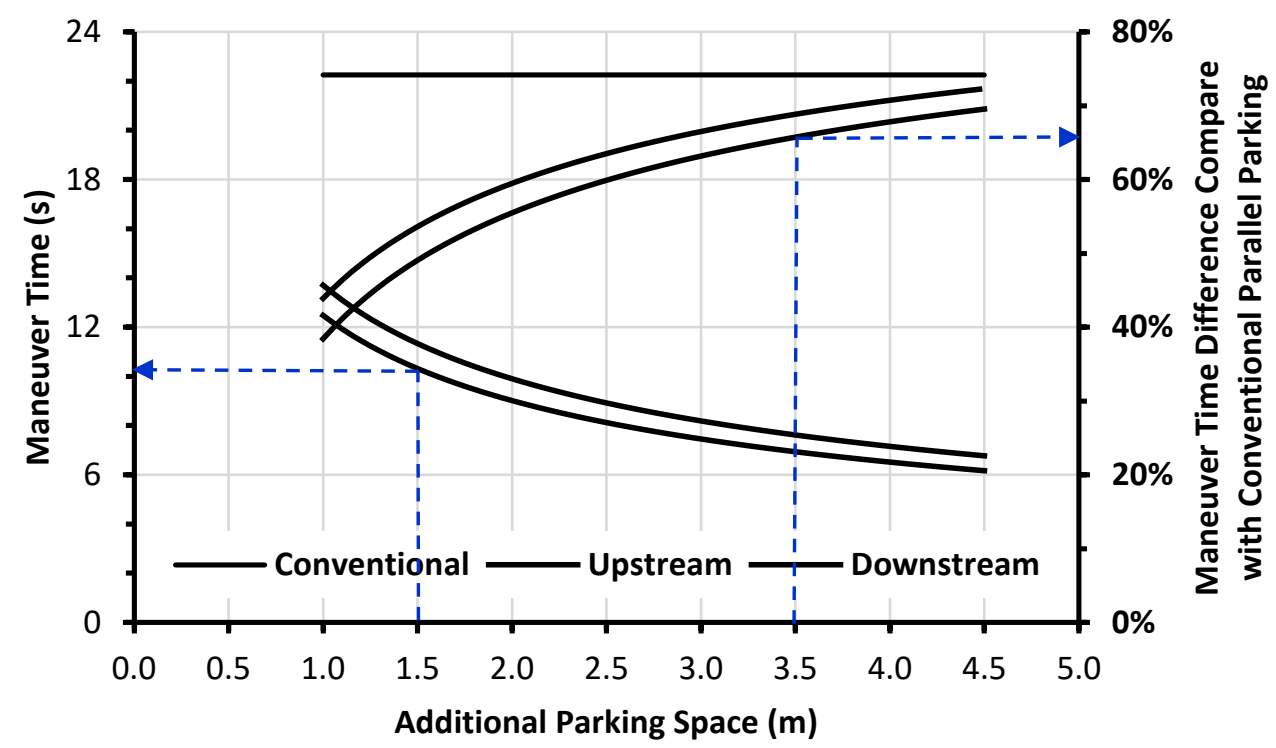

Fig. 8. Comparison of entry maneuver time 


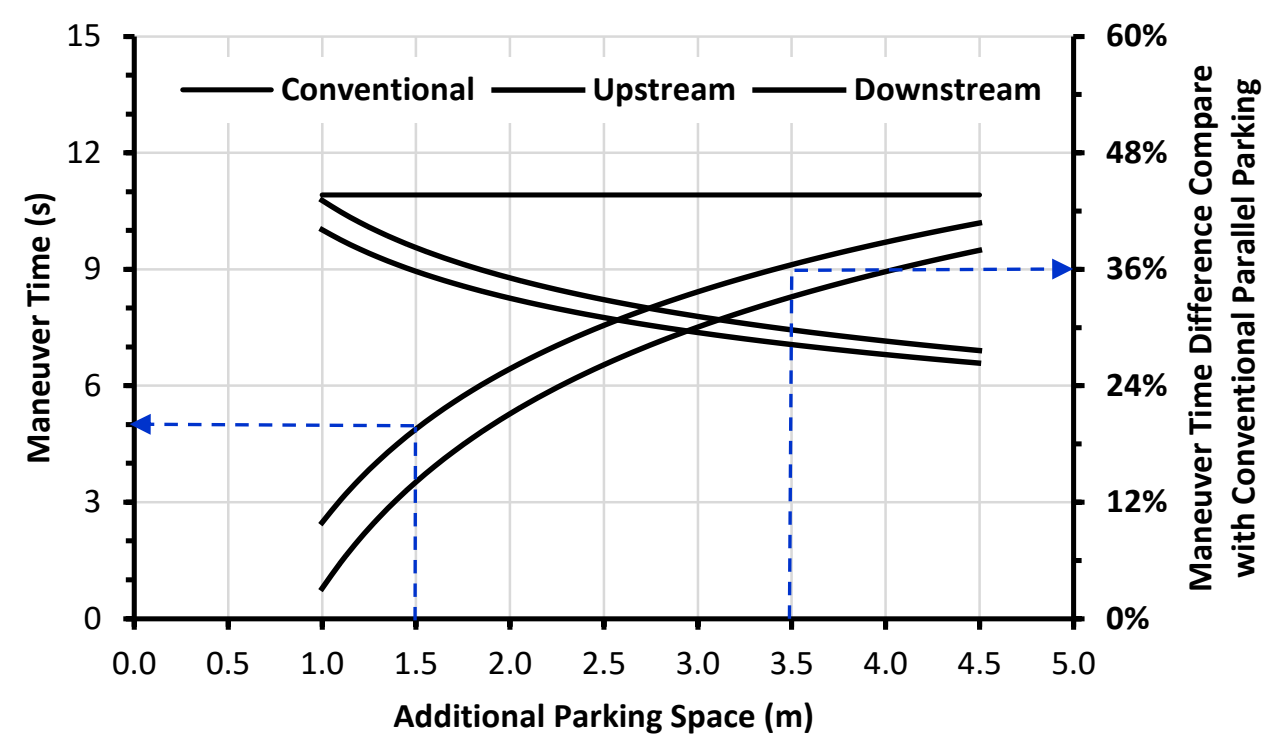

Fig. 9. Comparison of exit maneuver time

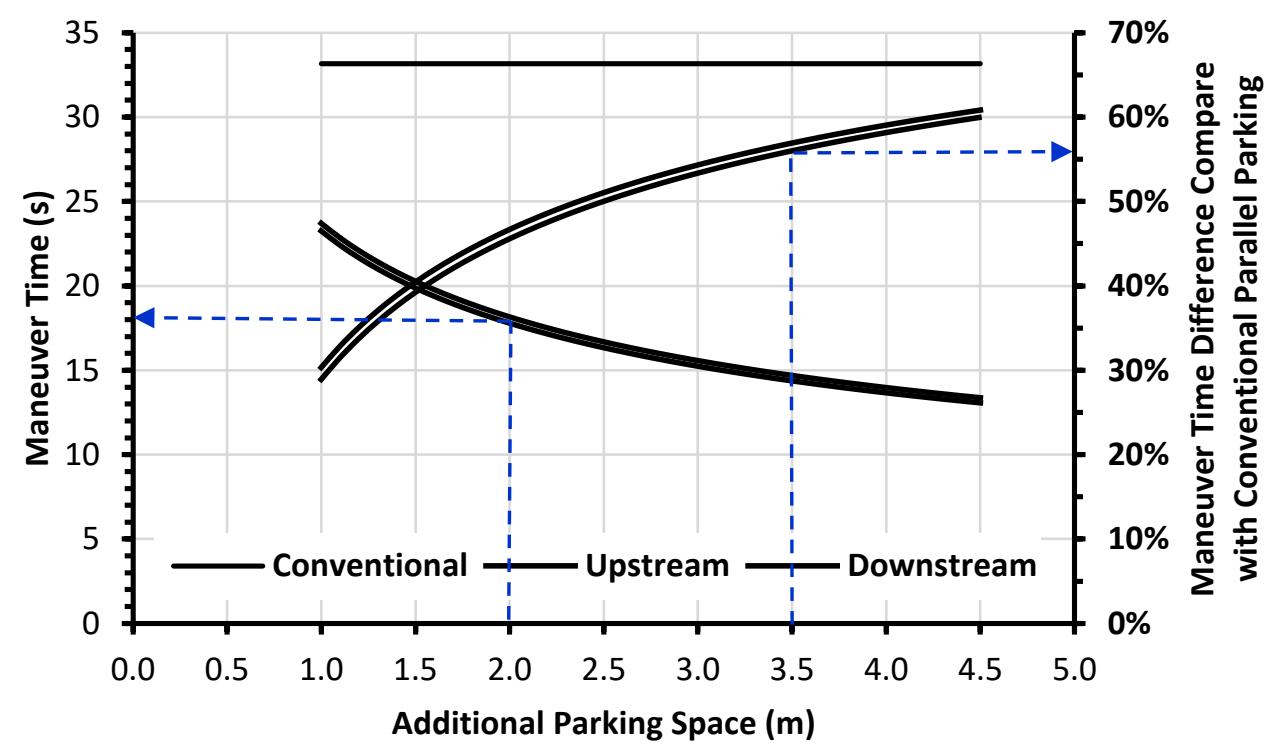

Fig. 10. Comparison of total maneuver time

Table 1 illustrated comparison between income from parking fee and loss due to delay time for stall length $=5.7 \mathrm{~m}$ and varies dimension of additional parking space. Column 1 and column 2 are number of parking space per 100 meters segment of on-street parking, e.g. for additional parking space $1.0 \mathrm{~m}$, number of parking space for upstream or downstream $=100 /(5.7+(1.0 / 2))=16.1$ parking space. 
Table 1. Income from parking fee

\begin{tabular}{|c|c|c|c|c|c|}
\hline $\begin{array}{c}\text { Additional } \\
\text { Parking Space }\end{array}(\mathrm{m})$ & \multicolumn{2}{|c|}{$\begin{array}{c}\text { Number of Parking } \\
\text { Space }\end{array}$} & \multicolumn{3}{c|}{ Income from Parking Fee (IDR/hour) } \\
\cline { 2 - 6 } & $\mathrm{C}$ & $\mathrm{U}$ and D & $\mathrm{C}$ & $\mathrm{U}$ and D & Difference \\
\cline { 2 - 6 } & $(1)$ & $(2)$ & $(3)$ & $(4)$ & $(5)$ \\
\hline 1.0 & 17.5 & 16.1 & 175,439 & 161,290 & $-8 \%$ \\
\hline 1.5 & 17.5 & 15.5 & 175,439 & 155,039 & $-12 \%$ \\
\hline 2.0 & 17.5 & 14.9 & 175,439 & 149,254 & $-15 \%$ \\
\hline 2.5 & 17.5 & 14.4 & 175,439 & 143,885 & $-18 \%$ \\
\hline 3.0 & 17.5 & 13.9 & 175,439 & 138,889 & $-21 \%$ \\
\hline 3.5 & 17.5 & 13.4 & 175,439 & 134,228 & $-23 \%$ \\
\hline 4.0 & 17.5 & 13.0 & 175,439 & 129,870 & $-26 \%$ \\
\hline 4.5 & 17.5 & 12.6 & 175,439 & 125,786 & $-28 \%$ \\
\hline
\end{tabular}

$\mathrm{C}=$ Conventional, $\mathrm{U}$ and $\mathrm{D}=$ Upstream and Downstream

*average between upstream and downstream

Table 2. Loss due to delay time

\begin{tabular}{|c|c|c|c|c|c|}
\hline $\begin{array}{c}\text { Additional } \\
\text { Parking Space } \\
(\mathrm{m})\end{array}$ & \multicolumn{2}{|c|}{$\begin{array}{c}\text { Total Maneuver Time } \\
(\mathrm{secs})\end{array}$} & \multicolumn{3}{|c|}{ Loss due to Delay Time (IDR/hour) } \\
\cline { 2 - 6 } & $\mathrm{C}$ & $\mathrm{U}$ and D & $\mathrm{C}$ & U and D & Difference \\
\cline { 2 - 6 } & $(1)$ & $(2)$ & $(3)$ & $(4)$ & $(5)$ \\
\hline 1.0 & 33.2 & 23.3 & $8,892,381$ & $5,741,143$ & $-35 \%$ \\
\hline 1.5 & 33.2 & 20.3 & $8,892,381$ & $4,805,548$ & $-46 \%$ \\
\hline 2.0 & 33.2 & 18.0 & $8,892,381$ & $4,110,719$ & $-54 \%$ \\
\hline 2.5 & 33.2 & 16.6 & $8,892,381$ & $3,645,685$ & $-59 \%$ \\
\hline 3.0 & 33.2 & 15.4 & $8,892,381$ & $3,260,912$ & $-63 \%$ \\
\hline 3.5 & 33.2 & 14.4 & $8,892,381$ & $2,964,268$ & $-67 \%$ \\
\hline 4.0 & 33.2 & 13.8 & $8,892,381$ & $2,736,908$ & $-69 \%$ \\
\hline 4.5 & 33.2 & 13.3 & $8,892,381$ & $2,547,517$ & $-71 \%$ \\
\hline
\end{tabular}

$\mathrm{C}=$ Conventional, $\mathrm{U}$ and $\mathrm{D}=$ Upstream and Downstream

*average between upstream and downstream

Based on number of parking space on column 1 and column 2, if parking turn over $=2$ and parking fee is fix IDR 5,000 per car, e.g. income from parking fee for upstream or downstream $=2 \times 16.1 \times 5.000=$ IDR 161,290. Column 5 show the difference income from parking fee between conventional parallel parking and upstream/downstream stall for varies additional parking space.

Total maneuver time for conventional and upstream /downstream stall are shown in Table 2 column 1 and column 2 respectively. Column 2 is average total maneuver time between upstream stall and downstream stall, because the value for each maneuver almost the same (Figure 10).

Column 3 and column 4 show the loss due to delay time causing by maneuver time for $\mathrm{VT}=\mathrm{IDR} 25.954 / \mathrm{pcu} /$ hour, traffic flow $=1.000 \mathrm{pcu} /$ hour, e.g. loss due to maneuver time for additional parking space $1.0 \mathrm{~m}=(16.1 \times 2 \times 23.3) / 3,600 \times 27,510 \times 1,000=$ IDR $5,741,143$ /hour. Column 5 show the difference loss due to delay time between conventional parallel parking and upstream/downstream stall for varies additional parking space. 


\section{Conclusions}

Tandem parallel parking both upstream stall and downstream stall, are a good option to reduce delay time causing by maneuver time compare with conventional parallel parking. Results indicate that, added one-meter additional parking space could reduce total maneuver time up to $29 \%$ for the upstream stall and $31 \%$ for the downstream stall, and also reduce $8 \%$ income from on-street parking fee, but also will reduce $35 \%$ loss due to delay time causing by parallel parking maneuver.

\section{References}

1. Wolf, C. C., Ocklenburg, S., Ören, B., Becker, C., Hofstätter, A., Bös, C., ... Güntürkün, O. Sex differences in parking are affected by biological and social factors. Psychological Research, 74(4), 429-435. (2010)

2. Reimer, B., Mehler, B., and Coughlin, J. F. An Evaluation of Driver Reactions to New Vehicle Parking Assist Technologies Developed to Reduce Driver Stress. New England University Transportation Center, 1-26. (2010)

3. $\mathrm{Su}, \mathrm{D}$., and Chan, K. Compensating for Operational Uncertainty in Man - Machine Systems: A Case Study on Intelligent Vehicle Parking Assist System, 1(September 2015), 1-13. http://doi.org/10.1115/1.4030438. (2017)

4. Cherise Threewitt. The 8 Best Self-Parking Cars. (2017)

5. Iowa Department of Transportation Office of Design. Parking on Urban Primary Highways Chapter 6C-8. (2010)

6. Essex Works. Parking Standards Design and Good Practice. (2009)

7. Setiawan, R., Kurniawan, W., and Tomasoa, S. H. P. Dampak Perubahan Dimensi Petak Parkir Terhadap Waktu Manuver Parkir Paralel. In Konferensi Nasional Teknik Sipil (KoNTekS) 4. (Sanur-Bali, 2-3 Juni 2010). (2010)

8. Faridli, M. M., and Kartika, A. A. G. Studi Kelayakan Pembangunan Jalan Lingkar Barat Dalam Kota Surabaya. Jurnal Teknik POMITS, 1(1), 1-6. (2013) 